\title{
GAMBARAN PASIEN RUJUKAN BPJS RAWAT JALAN DI POLI GIGI RUMAH SAKIT ALOE SABOE KOTA GORONTALO TAHUN 2017 DAN 2018
}

\author{
Ariyanto Mohi ${ }^{1}$, Vega Roosa Fione, ${ }^{2,}$ Youla Karamoy ${ }^{3}$ \\ 1)RS Aloe Saboe, Jl. Prof. Dr. H. Aloei Saboe No. 92,Kota Gorontalo \\ 2,3) Jurusan Keperawatan Gigi Poltekkes Kemenkes ManadoJl.RW Mongisidi Malalayang II Manado
}

Email : mohiariyanto@gmail.com

\begin{abstract}
ABSTRAK
Rumah sakit dituntut untuk memberikan pelayanan kesehatan yang memenuhi standar pelayanan yang optimal. Hal tersebut sebagai akuntabilitas rumah sakit supaya mampu bersaing dengan Rumah Sakit lainnya. Sistem rujukan pelayanan kesehatan merupakan penyelenggaraan pelayanan kesehatan yang mengatur pelimpahan tugas dan tanggung jawab pelayanan kesehatan secara timbale balik baik vertical maupun horizontal.Tujuan penelitian untuk mengetahui gambaran pasien rujukan BPJS Rawat Jalan di Poli Gigi RS Aloei Saboe Kota Gorontalo tahun 2017 dan 2018. Jenis penelitian yang digunakan adalah deskriptif. Teknik pengambilan sampel secara total populasi yaitu seluruh data pasien yang memeriksakan gigi di Poliklinik Gigi RS Aloei Saboe Kota Gorontalo Tahun 2017 dan 2018, yang berjumlah 4242 pasien. Teknik pengumpulan data adalah pencatatan data sekunder melalui bank data di rumah sakit. Data kemudian ditabulasi dan dianalisis, menggunakan tabulasi dengan prosentase. Hasil penelitian diketahui bahwa sebagian besar responden adalah perempuan yaitu $61,7 \%$ sedangkan responden laki-laki hanya 38,3\%. Untuk kategori umur responden pada penelitian ini, paling banyak adalah kelompok umur 34-44 tahun (27,6\%), sedangkan yang paling sedikit adalah kelompok umur lebih dari 56 tahun (10,2\%). Berdasarkan jenis kasus, menunjukkan bahwa pada tahun 2017 ada 16 kasus yang dirawat di RSUD Aloei Saboe dan paling banyak adalah Pulpitis (601 kasus) dan terendah adalah Kalkulus dan FrakturMahkota (masing-masing 5 kasus). Sedangkan untuk tahun 2018 ada 23 kasus yang dirawat dan paling banyak adalah Pulpitis (595 kasus) dan terendah adalah Tumor Palatum (2 kasus). Kesimpulan: Jumlah kunjungan didominasi oleh pasien perempuan dan pada kelompok umur 34-44 tahun dan adanya kenaikan jumlah kasus yang dirawat di tiap tahun.
\end{abstract}

\section{Kata Kunci : Pasien rujukan, BPJS, Poliklinik Gigi}

\section{ABSTRACT}

Hospitals are required to provide health services that meet optimal service standards. This is as a hospital's accountability so that it can compete with other hospitals. The health service referral system is the organization of health services that regulates the delegation of duties and responsibilities of health services both vertically and horizontally. The purpose of this study is to determine the description of BPJS Outpatient referral patients in the Dental Clinic of Aloei Saboe Hospital Gorontalo City in 2017 and 2018. This type of research is descriptive. The sampling technique in total population is the entire data of the patients who examined their teeth in the Dental Clinic of Aloei Saboe Hospital, Gorontalo City in 2017 and 2018, totaling 4242 patients. Data collection technique is the recording of secondary data through a data bank in a hospital. The data is then tabulated and analyzed, using tabulations with percentages. The results of the study revealed that the majority of respondents were female namely $61.7 \%$ while male respondents were only $38.3 \%$. For the age category of respondents in 
this study, most were the age group 34-44 years (27.6\%), while the least was the age group over 56 years $(10.2 \%)$. Based on the type of case, it shows that in 2017 there were 16 cases treated at Aloei Saboe Regional Hospital and the most were Pulpitis (601 cases) and the lowest were Calculus and Crown Fracture (5 cases each). Whereas for 2018 there were 23 cases treated and the most were Pulpitis (595 cases) and the lowest was Palatum Tumor (2 cases). Conclusion: The number of visits was dominated by female patients and in the 34-44 age group and there was an increase in the number of cases treated each year.

Keywords: Referral patients, BPJS, Dental clinic

\section{PENDAHULUAN}

Rumah sakit dituntut untuk memberikan pelayanan kesehatan yang memenuhi standar pelayanan yang optimal.Hal tersebut sebagai akuntabilitas rumah sakit supaya mampu bersaing dengan Rumah Sakit lainnya. Rumah sakit adalah bentuk organisasi pelayanan kesehatan yang bersifat komprehensif, mencakup aspek promotif, preventif, kuratif dan rehabilitatif, serta sebagai pusat rujukan kesehatan masyarakat. Rumah sakit merupakan organisasi dengan kompleksitas yang sangat tinggi. Sering kali rumah sakit diistilahkan sebagai organisasi yang padat modal, padat sumber daya manusia, padat teknologi, padat ilmu pengetahuan dan padat regulasi ${ }^{1}$

Rumah Sakit Umum Daerah Prof. Dr. H. Aloei Saboe Kota Gorontalo adalah Rumah Sakit type B dan merupakan Rumah Sakit Pendidikan Keperawatan dengan kapasitas 350 tempat tidur dan jumlah perawat $44,21 \%$ dari 889 tenaga kerja keseluruhan. Rumah sakit ini juga menjadi Rumah Sakit rujukan bagi daerah sekitar Kota Gorontalo lainnya seperti Kabupaten Pohuwato, Bone Bolango, Boalemo, Gorontalo Utara dan Kabupaten Gorontalo. ${ }^{6,7}$

Badan Pelaksana Jaminan Sosial atau yang disingkat BPJS Kesehatan sebagai badan pelaksana merupakan badan hukum yang dibentuk untuk menyelenggarakan program jaminan kesehatan untuk seluruh masyarakat indonesia (Permenkes No 71, 2013 pasal 1:2). Manfaat JKN BPJS kesehatan meliputi pelayanan kesehatan tingkat pertama yaitu pelayanan kesehatan non spesialistik dan pelayanan kesehatan rujukan tingkat lanjutan yaitu pelayanan kesehatan mencakup rawat jalan dan rawat inap. Pelayanan kesehatan dilaksanakan secara berjenjang dimulai dari pelayanan kesehatan tingkat pertama, pelayanan kesehatan tingkat kedua (rumah sakit umum kabupaten/kota) hanya dapat diberikan atas rujukan dari pelayanan kesehatan tingkat pertama, pelayanan kesehatan tingkat ketiga (rumah sakit umum propinsi/pusat) hanya dapat di berikan atas rujukan dari pelayanan kesehatan tingkat kedua atau tingkat pertama, kecuali pada keadaan gawat darurat, kekhususan permasalahan aturan BPJS Kesehatan (Permenkes No 28, tahun 2014). Rujukan bagi pasien BPJS di buat di Fasilitas pelayanan tingkat pertama. $^{2}$

Sistem rujukan pelayanan kesehatan merupakan penyelenggaraan pelayanan kesehatan yang mengatur pelimpahan tugas dan tanggungjawab pelayanan kesehatan secara timbal balik baik vertikal maupun horizontal. Rujukan vertikal merupakan rujukan antar pelayanan kesehatan yang berbeda tingkatan dapat dilakukan dari tingkatan pelayanan yang lebih rendah ke tingkatan pelayanan yang lebih tinggi atau sebaliknya sedangkan rujukan horizontal merupakan rujukan antar pelayanan 
kesehatan dalam satu tingkatan, dilakukan apabila perujuk tidak dapat memberikan pelayanan kesehatan sesuai dengan kebutuhan pasien karena keterbatasan fasilitas, peralatan dan/atau ketenagaan yang sifatnya sementara atau menetap (PMK No. 001 Tahun 2012). Era Jaminan Kesehatan Nasional memberlakukan sistem rujukan yang berjenjang, dimana pelayanankesehatan dimulai di fasilitas kesehatan tingkat pertama (BPJS Kesehatan, 2014). Diberlakukannya sistem rujukan berjenjang mengharuskan pasien BPJS untuk mengutamakan berobat ke puskesmas yang merupakan fasilitas pelayanan primer. Jika pasien tidak dapat ditangani di fasilitas pelayanan primer baru diberlakukan rujukan pasien ke fasilitas pelayanan sekunder,yaitu Rumah Sakit. $^{2}$

Berdasarkan penelitian yang dilakukan oleh Siregar (2018) didapatkan bahwa ketersediaan obat-obat terhadap penyakit kronis, serta kurangnya ketersediaan fasilitas kesehatan dan bahan habis pakai menjadi faktor utama yang merupakan alasan perujukan ke faskes yang lebih tinggi. ${ }^{3}$ Tingginya jumlah rujukan pasien BPJS telah dilaporkan oleh Talib dan Ilmi (2017) rasio rujukan ke fasilitas kesehatan tingkat II yang dilakukan oleh Puskesmas Gamping I Sleman Yogyakarta mencapai $91.5 \%$ yang melebihi dari standar BPJS yaitu $15 \%$. Dengan rasio rujukan ke rumah sakit swasta sebesar $(91,5 \%)$ dan rumah sakit pemerintah $(8,5 \%)$. Berdasarkan data tersebut menunjukan rasio rujukan pasien ke rumah sakit swasta cukup tinggi, seharusnya hal ini tidak bisa terjadi karena di Era JKN, puskesmas harus mampu melaksanakan 144 diagnosa secara baik dan tuntas, ini akan berdampak pada rumah sakit penerima rujukan, keadaan ini menggambarkan bahwa Puskesmas Gamping 1 Sleman Yogyakarta belum dapat menjalankan fungsinya secara optimal sebagai pintu masuk atau penapis rujukan (gatekeeper). ${ }^{4}$ Masih tingginya angka rujukan pasien menunjukkan bahwapuskesmas belum dapat melakukan pelayanankesehatannya secara optimal sebagaigate keeperpelayanan kesehatan dalam masyarakat. Fungsigate keeper puskesmas yaitu untuk mengkoordinir pelayanan kesehatan pada masyarakat dan untuk memaksimalkan efisiensi serta meningkatkan efektifitas pelayanan. ${ }^{5}$

Berdasarkan data yang diperoleh dari bank data dan register kunjungan pasien di Poli Gigi RS Aloei Saboe Kota Gorontalo Tahun 2017 dan 2018 menunjukkan bahwa total data kunjungan pasien berjumlah 4242 pasien. Dimana pada tahun 2017 hanya 1988 pasien dan tahun 2018 meningkat menjadi 2254. Dari uraian data tersebut maka penulis tertarik untuk meneliti tentang gambaran pasien rujukan BPJS Rawat Jalan di Poli Gigi RS Aloei Saboe Kota Gorontalo pada tahun 2017 dan 2018. , $^{6}$

Tujuan penelitian ini adalah mengetahui gambaran pasien rujukan BPJS Rawat Jalan di Poli Gigi RS Aloei SaboeKota Gorontalo tahun 2017 dan 2018.

\section{METODE}

Jenis penelitian ini merupakan penelitian deskriptif, yang bertujuan untuk menggambarkan atau mendeskripsikan fenomena yang terjadi pada suatu populasi tertentu ${ }^{8}$

Variabel penelitian ini adalah variabel tunggal yaitu : Pasien rujukan BPJS rawat jalan di Poli Gigi RS Aloei Saboe yang dibedakan berdasarkan umur, jenis kelamin dan jenis kasus.

Waktu penelitian dilaksanakan pada bulan Juni 2019. Lokasi penelitian dilaksanakan di Poliklinik gigi RS Aloei Saboe Kota Gorontalo..

Populasi dan Sampel :

1. Populasi dalam penelitian ini yaitu seluruh pasien yang memeriksakan gigi di Poliklinik Gigi RS Aloei Saboe Kota Gorontalo Tahun 2017 dan 2018. 
2. Sampel yang digunakan dalam penelitian ini adalah Sampel dalam penelitian ini adalah total populasi yaituseluruh data pasien yang memeriksakan gigi di Poliklinik Gigi RS Aloei Saboe Kota Gorontalo Tahun 2017 dan 2018, yang berjumlah 4242 pasien.

Variabel Penelitian ini adalah variabel tunggal yaitu : Pasien rujukan BPJS rawat jalan di Poli Gigi RS Aloei Saboe yang dibedakan berdasarkan umur, jenis kelamin dan jenis kasus.

\section{Defenisi Operasional}

1. Pasien rujukan adalah setiap orang yang melakukan konsultasi masalah kesehatannya untuk memperoleh pelayanan kesehatan yang diperlukan baik secara langsung maupun tidak langsung kepada dokter atau dokter gigi, yang membawa surat rujukan atau surat pengantar tenaga medis (dokter maupun dokter gigi) secara tertulis yang bertujuan sebagai advice (petunjuk pengobatan) maupun pengobatan secara lebih lanjut kepada tenaga medis yang lebih berkompeten dalam bidangnya.

2. Pasien rujukan berdasarkan umur adalah usia responden dihitung berdasarkan tahun kelahiran. Umur dikelompokkan dalam 5 kelompok yaitu : $12-22,23-33,34-44$, $45-55,>56$ tahun.

3. Pasien rujukan berdasarkan jenis kelamin adalah perbedaan bentuk, sifat, dan fungsi biologi laki-laki dan perempuan yang menentukan perbedaan peran mereka dalam menyelenggarakan upaya meneruskan garis keturunan.

4. Jenis kasus adalah macam-macam penyakit berdasarkan diagnose dokter gigi.

Instrumen yang digunakan dalam penelitian ini adalah data kunjungan pasien BPJS rawat jalan yang dirujuk ke poli gigi Rumah Sakit Aloe
Saboe Kota Gorontalo, yang diambil dari bank data Rumah Sakit.

Teknik pengumpulan data dalam penelitian ini yaitu dengan cara observasi pada data sekunder tentang pasien rujukan di Poli Gigi Rumah Sakit Aloe Saboe Kota Gorontalo tahun 2017 dan 2018.

Data yang diperoleh kemudian ditabulasi dan disajikan dalam bentuk tabel yang disertai dengan penjelasan. Dengan menggunakan rumus distribusi frekuensi

$$
\mathrm{p}=\frac{f}{\mathrm{~N}} \quad \mathrm{X} 100 \%
$$

Keterangan :

$\mathrm{F}=$ frekwensi yang sedang dicari

$\mathrm{N}=$ Number of cases (jumlah frekwensi kebanyakan individu)

$\mathrm{P}=$ Angka presentasi ${ }^{9}$

\section{HASIL DAN PEMBAHASAN}

\section{HASIL}

Rumah Sakit Umum Daerah Prof. Dr. H. Aloei Saboe Kota Gorontalo berkedudukan di jalan Prof. Dr. H. Aloei Saboe Nomor 91 RT 1 RW 4 Kelurahan Wongkaditi Timur Kecamatan Kota Utara Gorontalo Provinsi Gorontalo, terletak diarea lahan seluas $54.000 \mathrm{~m}^{2}$.

Penelitian ini dilakukan dengan mengalisa buku register kunjungan pasien Poliklinik Gigi RS Aloei Saboe selama tahun 2017 dan tahun 2018 yang berjumlah 4242 pasien. 
Tabel 1.Distribusi pasien rujukan BPJS rawat jalan di RSUD Aloei Saboe Kota Gorontalo berdasarkan jenis kelamin

\begin{tabular}{ccccc}
\hline $\begin{array}{c}\text { Jenis } \\
\text { Kelamin }\end{array}$ & $\mathbf{2 0 1 7}$ & $\mathbf{2 0 1 8}$ & $\mathbf{n}$ & $\mathbf{\%}$ \\
\hline Laki-laki & 737 & 888 & 1625 & 38,3 \\
Perempuan & 1251 & 1366 & 2617 & 61,7 \\
\hline Total & & & $\mathbf{4 2 4 2}$ & $\mathbf{1 0 0}$ \\
\hline
\end{tabular}

Pada tabel 1 terlihat bahwa sebagian besar responden adalah perempuan yaitu 61,7 \% sedangkan responden laki-laki hanya 38,3\%.

Tabel 2.Distribusi pasien rujukan BPJS rawat jalan di RSUD Aloei Saboe Kota Gorontalo berdasarkan umur

\begin{tabular}{ccccc}
\hline $\begin{array}{c}\text { Kelompok } \\
\text { Umur }\end{array}$ & $\mathbf{2 0 1 7}$ & $\mathbf{2 0 1 8}$ & $\mathbf{n}$ & $\mathbf{\%}$ \\
\hline $12-22$ & 427 & 406 & 833 & 19,6 \\
$23-33$ & 514 & 486 & 1000 & 23,6 \\
$34-44$ & 515 & 654 & 1169 & 27,6 \\
$45-55$ & 410 & 396 & 806 & 19 \\
$>56$ & 217 & 217 & 434 & 10,2 \\
\hline Total & $\mathbf{2 0 8 3}$ & $\mathbf{2 1 5 9}$ & $\mathbf{4 2 4 2}$ & $\mathbf{1 0 0}$ \\
\hline
\end{tabular}

Pada tabel 2 dapat dilihat bahwa responden pada penelitian ini, paling banyak adalah kelompok umur 34-44 tahun (27,6\%), sedangkan yang paling sedikit adalah kelompok umur lebih dari 56 tahun $(10,2 \%)$.
Tabel 3. Jumlah pasien rujukan BPJS rawat jalan di RSUD Aloei Saboe Kota Gorontalo berdasarkan jenis kasus

\begin{tabular}{lcccc}
\hline $\begin{array}{l}\text { Jenis Kasus } \\
\text { berdasarkan } \\
\text { diagnose medis }\end{array}$ & $\begin{array}{c}\text { Tahun } \\
\mathbf{2 0 1 7}\end{array}$ & $\begin{array}{c}\text { Tahun } \\
\mathbf{2 0 1 8}\end{array}$ & Jumlah & \% \\
\hline Abses & 268 & 308 & 576 & 13,6 \\
Pulpitis & 460 & 498 & 958 & 22,6 \\
Gangren pulpa & 402 & 431 & 833 & 19,6 \\
Hiperemi pulpa & 292 & 335 & 627 & 14,8 \\
Impaksi & 168 & 180 & 348 & 8,2 \\
Periodontitis & 202 & 309 & 511 & 12,0 \\
Persistensi & 25 & 25 & 50 & 1,2 \\
Kalkulus & 5 & 12 & 17 & 0,4 \\
Epulis & 12 & 25 & 37 & 0,9 \\
Pulpa polip & 11 & 26 & 37 & 0,9 \\
Gingivitis & 68 & 86 & 154 & 3,6 \\
Fraktur mahkota & 5 & 0 & 5 & 0,1 \\
Suspect & 6 & 15 & 21 & 0,5 \\
mucocele & & & & \\
Fraktur maxilla & 8 & 0 & 8 & 0,2 \\
Stomatitis & 6 & 8 & 14 & 0,33 \\
Fraktur & 0 & 13 & 13 & 0,31 \\
mandibula & & 5 & 5 & 0,1 \\
Palaktosizis & 0 & 2 & 2 & 0,05 \\
Tumor palatum & 0 & 8 & 0,2 \\
Apical penetrasi & 0 & 8 & 6 & 0,14 \\
Ameloblastoma & 0 & 6 & 4 & 0,09 \\
Fibroma & 0 & 4 & 8 & 0,2 \\
\hline Perikoronitis & 0 & 8 & $\mathbf{4 2 4 2}$ & $\mathbf{1 0 0}$ \\
\hline$\quad$ Total kasus & $\mathbf{1 9 3 8}$ & $\mathbf{2 3 0 4}$ & & \\
\hline & & & & \\
\hline
\end{tabular}

Tabel 3 menunjukkan bahwa pada tahun 2017 ada 15 kasus yang dirawat di RSUD Aloei Saboe dan paling banyak adalah pulpitis yaitu 460 kasus dan terendah adalah kalkulus dan fraktur mahkota masing-masing 5 kasus. Sedangkan untuk tahun 2018 ada 20 kasus yang dirawat dan paling banyak adalah pulpitis yaitu 498 kasus dan terendah adalah tumor palatum sebanyak 2 kasus. Secara keseluruhan 5 kasus teratas yang dirawat di RSUD Aloei Saboe selang tahun 2017 dan 2018 adalah pulpitis (22,6\%), gangraen pulpa $(19,6 \%)$, hiperemi pulpa $(14,8 \%)$, abses $(13,6 \%)$ dan periodontitis $(12,0 \%)$. 


\section{PEMBAHASAN}

Manfaat Pelayanan Kesehatan Gigi dan Mulut dalam Jaminan Kesehatan Nasional (JKN) Menurut Permenkes Nomor 71 tahun 2013 tentang Pelayanan Kesehatan Pada Jaminan Kesehatan Nasional, Fasilitas Kesehatan adalah fasilitas pelayanan kesehatan yang digunakan untuk menyelenggarakan upaya pelayanan kesehatan perorangan, baik promotif, preventif, kuratif maupun rehabilitatif yang dilakukan oleh Pemerintah, Pemerintah Daerah, dan/atau Masyarakat. Adalah hal yang baru dan inovatif dalam era JKN dimana Fasilitas kesehatan yang menyelenggarakan pelayanan kesehatan untuk peserta JKN disebut dengan Fasilitas Kesehatan Tingkat Pertama (FKTP) dan Fasilitas Kesehatan Rujukan Tingkat Lanjutan (FKRTL) yang dimaksud adalah: Puskesmas atau yang setara,Praktik Dokter, Praktik Dokter Gigi, Klinik Pratama atau yang setara. ${ }^{2}$

Poliklinik gigi RSAloei Saboe merupakan Fasilitas Kesehatan Rujukan Tingkat Lanjutan yang melayani pelayanan rawat jalan serta menerima rujukan dari FKTP.Jumlah kunjungan pasien di Poli Gigi RS Aloei SaboeKota Gorontalo terus meningkat setiap tahunnya. Hasil penelitian ini menunjukkan kenaikan jumlah kunjungan yaitu pada tahun 2017 ada 1938 pasien dan tahun 2018 menjadi 2304 pasien.Pada Tabel 3 dapat dilihat bahwa di tahun 2017 hanya 15 kasus yang dirawat di RSUD Aloei Saboedan pada tahun 2018 menjadi 20 kasus. Kasus yang paling sering dan paling banyak adalah Pulpitis yaitu 958 kasus dan terendah adalah Tumor Palatum yaitu 2 kasus. ${ }^{6,7}$

Penelitian ini menunjukkan bahwa terjadinya peningkatan jumlah kasus dan diikuti dengan jenis kasus yang semakin kompleks disetiap tahunnya.Hal ini merupakan salah satu indikasi pemanfaatan jaminan kesehatan yang diberikan pemerintah kepada masyarakat Indonesia termasuk masyarakat di Gorontalo melalui BPJS.Manfaat yang didapat oleh peserta BPJS kesehatan mencakup pelayanan pencegahan dan pengobatan termasuk pelayanan obat dan bahan medis habis pakai sesuai dengan kebutuhan medis. Pada saat berobat hanya perlu mengikuti prosedur yang ditetapkan BPJS dan menunjukan kartu kepesertaan untuk mendapatkan layanan kesehatan sesuai kebutuhan, dengan biaya kesehatan gratis untuk semua jenis penyakit. Sehingga terjadi perubahan pola pikir masyarakat, dimana masyarakat yang dahulu merasa kesulitan berobat karena biaya yang cukup mahal lebih memilih membiarkan penyakit dan tidak berobat. Tetapi sekarang dengan adanya sistem JKN melalui BPJS masyarakat mau berobat ke sarana-saranan pelayanan kesehatan termasuk rumah sakit.

Berdasarkan penelitian ini diketahui bahwa pada tahun 2017 dan 2018 ada 20 kasus yang dirawat di RSUD Aloei Saboe(tabel 3). Adapun 5 kasus teratas yang paling mendominasi dari temuan ini adalah pulpitis $(22,6 \%)$, gangraen pulpa $(19,6 \%)$, hiperemi pulpa $(14,8 \%)$, abses $(13,6 \%)$ dan periodontitis $(12,0 \%)$. Dari 5 kasus yang paling dominan ini semuanya berhubungan dengan adanya karies gigi. Karies gigi masih merupakan masalah bagi masyarakat Indonesia termasuk di Provinsi Gorontalo. Berdasarkan data Riset Kesehatan Dasar (RISKESDAS) tahun 2013 Indeks DMF-T untuk Provinsi Gorontalo sebesar 4,3 yang berarti setiap penduduk mempunyai 4 sampai 5 gigi yang karies atau pernah mengalami karies. Angka ini menunjukkan kerusakan gigi penduduk di Gorontalomasih termasuk kategori tinggi. 10 Rongga mulut merupakan salah satu pintu masuk bakteri penyebab penyakit ke bagian tubuh lainnya, baik aerob maupun anaerob. Bakteri pada rongga mulut ternyata dapat menyebar melalui aliran darah, yang disebut dengan bakteremia.Jika kesehatan mulut baik maka bakteri yang dapat masuk ke dalam aliran darah hanya sedikit dan tidak membahayakan tubuh. Namun jika kesehatan mulut tidak dalam keadaan baik, maka jumlah bakteri yang akan masuk ke 
dalam aliran darah meningkat dua hingga sepuluh kali lipat. Hal tersebut dapat meningkatkan peluang terjadinya bakteremia menjadi lebih besar.

Tanpa kebersihan mulut yang tepat, bakteri juga dapat mencapai tingkat yang menyebabkan infeksi mulut, seperti kerusakan gigi dan penyakit gusi. Bahkan, teori fokal infeksi menyebutkan bahwa infeksi pada rongga mulut bertanggung jawab pada terjadinya tiga penyakit sistemik, yaitu penyakit kardiovaskuler, diabetes mellitus dan aterosklerosis.

\section{KESIMPULAN}

Berdasarkan hasil penelitian ini dapat ditarik kesimpulan bahwa :jumlah kunjungan pasien BPJS rawat jalan meningkat dari tahun 2017 dan tahun 2018.

1. Jumlah kunjungan responden perempuan lebih banyak dibandingkan laki-laki.

2. Jumlah kunjungan responden paling banyak adalah kelompok umur 34-44 tahun sedangkan yang paling sedikit adalah kelompok umur lebih dari 56 tahun.

3. Adanya kenaikan jumlah kasus yang dirawat di tahun 2017 hanya 15 kasus dan pada tahun 2018 menjadi 20 kasus. Kasus paling dominan adalah Pulpitis dan terendah adalah tumor palatum.

\section{SARAN}

Bagi pihak Rumah Sakit dan petugas poliklinik gigi disarankan untuk :

1. Menambah fasilitasberupa poster-poster, baners yang berisi pesan-pesan kesehatan gigi dan dipasang disekitar ruangan poliklinik gigi agar bisa dibaca dan dilihat oleh pasien, serta membuat leaflet yang berisi pesan-pesan kesehatan gigi yang bisa dibagi ke pasien.

2. Bagi petugas poliklinik gigi agar dapat mengoptimalkan pemberian informasi kesehatan gigi disamping kursi gigi selama proses perawatan (chair side talk).

\section{DAFTAR PUSTAKA}

1. Salimah, S. (2009, April 22). Training Need Analysis (TNA) di Rumah Sakit .Diakses tanggal 26 Mei 2019, dari http://indosdm.com/training-need-analysistnadi-rumah-sakit.

2. Badan Penyelenggara Jaminan Sosial, (2014). Panduan Layanan bagi Peserta BPJS Kesehatan.

3. Siregar,NAS (2018). Faktor-Faktor yang Mempengaruhi Rujukan Pasien Peserta Badan Penyelenggara Jaminan Sosial (BPJS) di Puskesmas Sigambal Kabupaten Labuhanbatu Tahun 2018. Skripsi FKM USU

4. Talib N, Ilmi, L.R (2017) Tinjauan Pelaksanaan Sistem Rujukan Pasien BPJS di Puskesmas Gamping I Sleman Yogyakarta Tahun 2017.Skripsi. Univ.Jend.Ahmad Yani Jogyakarta.

http://repository.unjaya.ac.id/2479/ Diakses tgl 3 Mei 2019

5. Zuhrawardi 2007 Skripsi analisis faktor pelaksanaan rujukan rawat jalan tingkat pertama peserta wajib PT. Askes pada tiga Puskesmas di Kota Banda Aceh Tahun 2007Universitas Sumatra utara. Medan

6. Profil Poliklinik Gigi RS.Aloei Saboe.Kota Gorontalo Tahun 2017

7. Profil Poliklinik Gigi RS.Aloei Saboe.Kota Gorontalo Tahun 2018

8. Sugiyono, 2013 Metode Penelitian Kuantitatif, Kualitatif, dan R\&D . Cet. XIX; Bandung: Alfabeta. 
9. Sudijono, A (2015). Pengantar Evaluasi Pendidikan Ed. 1, Cet. 14. Jakarta: PT RajaGrafindo Persada

10. Kementerian Kesehatan RI., 2013. Riset Kesehatan Dasar, Badan Penelitian \& Pengembangan Tenaga Kesehatan Kemenkes. Laksana, Jakarta 